\title{
NICOLÁS GUILLÉN: \\ O ITINERÁRIO DE UM POETA
}

POR

ADELTO GONÇALVES

Universidade do São Paulo, Brasil

Escrever de Nicolás Guillén é penetrar nas raízes africanas do povo cubano. Sua poesia, embora resgate muito das tradições africanas e tenha nascido nos anos 30 quando então era moda o negrismo entre os artistas europeus, é, antes de tudo, uma síntese da alma cubana. Até o seu surgimento, a cultura negra e suas manifestações artísticas em Cuba se mantinham confinadas, quando não desprezadas e rechaçadas até mesmo pelos mulatos que já haviam ascendido socialmente, mas que preferiam escamotear suas origens.

Guillén é, com certeza, na poesia, ao lado do escritor peruano José María Arguedas no romance, o caso mais significativo de simbiose cultural na América Latina. Sua obra foi uma contribuição decisiva para que o sociólogo e antropólogo também cubano Fernando Ortiz criasse em 1940 o neologismo transculturação, hoje indispensável para a compreensão da «historia de Cuba e, por razões análogas, a de toda a América em geral» ${ }^{1}$. Esse vocábulo, sem dúvida, é o que melhor expressa as diferentes fases do processo transitivo de uma cultura para outra. Transculturação não consiste apenas em se adquirir uma cultura distinta, como, a rigor, indica o termo inglês acculturation, mas é, isso sim, «um processo que implica necessariamente a perda ou desenraizamento de uma cultura precedente. Significa, sobretudo, a conseqüente criação de novos fenômenos culturais» ${ }^{2}$.

\footnotetext{
1 Fernando Ortiz, Contrapunteo cubano del tabaco y el azúcar, p. 135.

${ }^{2}$ Ibid., p. 135.
} 
Em Guillén, a princípio, não se percebe a influência indígena, mas ela existe como produto também do fenômeno transculturador iniciado com a chegada dos brancos que, com eles, trouxeram os negros, primeiro da Espanha, então já cheia de escravos procedentes de Guiné e do Congo, e, mais tarde, diretamente da África com a instalação do tráfico negreiro ${ }^{3}$. Assim, Cuba recebeu desde a Descoberta diversas culturas, umas tão selvagens como a dos índios ciboneies, que já habitavam a ilha, outras de avançada barbárie como a dos tainos, indígenas que já estavam em terras cubanas à chegada do invasor europeu e cuja língua deu origem ao crioulo haitiano, e outras ainda de maior complexidade econômica e social, como a dos iorubas, negros que também vieram para o Brasil e que, na África, já dispunham de noções de agricultura, moedas e até governos centralizados.

Segundo Ortiz, esses negros traziam culturas intermediárias entre os tainos e os astecas — dominavam metais, mas não tinham escrituraDessa associação, resultou uma nova realidade, composta e complexa, um fenômeno novo, original e independente. É por isso que Nicolás Guillén, descendente de iorubas — povo negro do grupo sudanês da África Ocidental, que vive no Sudoeste da Nigéria, no Daomé e no Togo-, pode ser chamado de o poeta da síntese, como o definiu o ensaísta Alfred Melon, de Martinica ${ }^{4}$.

Em seus poemas, ao contrário do que alguns críticos tentaram demonstrar quando seu some surgiu em Cuba, não há um dialeto negro, mas apenas as características do espanhol cubano popular. Na verdade, há séculos não existe uma fonética negra diferente do resto dos cubanos. Por isso, na poesia de Guillén, o que existe são recursos estilísticos e onomatopéias, que, com certeza, os negros transferiram para o espanhol falado em Cuba. Mas não é só. Tanto na poesia de Guillén como no próprio linguajar cubano podemos surpreender a presença de indigenismos, vocábulos provenientes do taino como ajíaco, mamey, maraca e outros.

Esses indigenismos, que há séculos estão incorporados ao falar cubano, na obra de Guillén, aparecem principalmente em Motivos de Son, livro com que o poeta estreou em 1930. Esse livro, que reúne os oito poemas publicados no dia 20 de abril daquele ano na página Ideales de una raza, dedicada à discussão de problemas dos negros, do jornal conservador Diario de la Marina, de Havana, introduz na poesia escrita o son, ritmo musical essencialmente cubano surgido do processo de transculturação afro-espanhol-indígena. A princípio, son significava apenas música, baile

\footnotetext{
${ }^{3}$ Ibid., p. 133.

${ }^{4}$ Alfred Melon, Tres ensayos sobre Nicolás Guillén, p. 52.
} 
ou canto de negros e, Alejo Carpentier ${ }^{5}$, tem antecedentes remotos numa canção do século XVI em homenagem a Ma Teodora, uma negra tocadora de bandola (bandolim, instrumento de quatro cordas), muito popular em Havana por volta de 1580 . A característica dessa canção é a repetição de um estribilho, num estilo similar às ladaínhas cantadas em procissões ou ritos litúrgicos e aos spirituals dos negros norte-americanos:

\section{Donde está la Ma Teodora? \\ Rajando la leña está. \\ Con su palo y su bandola? \\ Rajando la leña está. \\ Donde está que no la veo? \\ Rajando la leña está.}

Fernando Ortiz vai mais longe ao assinalar a presença desses estribilhos na totalidade dos cantos iorubas ${ }^{6}$. Não podemos, porém, esquecer que já existia uma tradição semelhante do uso do estribilho no canto e na poesia espanhola e portuguesa. E que, desde o começo do século XVI, espanhóis e portugueses passaram a transmitir aos povos da África seus usos e costumes. Se foram, no entanto, dos espanhóis e portugueses que oś africanos herdaram essa tradição, é difícil precisar. Afinal, o colonizador não tinha interesse em ensinar sua língua ao escravo. Pelo contrário. Uma das técnicas de dominação era trazer para o novo mundo pequenos grupos de africanos de tribos diferentes, que falavam idiomas distintos, com o objetivo de impedir que se unissem por uma língua comum e tentassem se revoltar. De qualquer modo, o que parece mais certo é que esse tipo de poesia, com reiteração, é de caráter universal.

Seja como for, a repetição à vontade de um estribilho com acompanhamento de instrumentos rudimentares parece haver sido a fase primária do son como gênero musical. $\mathrm{O}$ mérito de Guillén foi ter adaptado esse gênero musical à poesia escrita numa época em que Cuba não havia ainda se assumido como país mulato, embora as estatísticas oficiais sobre a população já pudessem prová-lo. Por isso, os oito poemas de Motivos de Son, quando surgiram, provocaram um certo mal-estar entre os negros e mestiços que já se haviam infiltrado na alta sociedade branca. Não era o que eles queriam ouvir, até porque aqueles versos os obrigavam a se recordar de uma origem social que queriam esquecer ou, pelo menos, fazer como se nunca houvesse existido. Em palavras do próprio Guillén, essas pessoas

\footnotetext{
${ }^{5}$ Alejo Carpentier, La música en Cuba, p. 30.

${ }^{6}$ Ángel Augier, prólogo de El libro de los sones, Nicolás Guillén, p. 7
} 
«haviam chegado penosamente à aristocracia desde a cozinha e tremiam quando viam uma panela» ${ }^{7}$.

$\mathrm{Na}$ verdade, o que irritava — brancos, negros e mestiços mais bem situados na escala social- era o fato de Guillén converter em arte tipos e situações que estavam a qualquer hora nas ruas de Havana e de todas as cidades cubanas. Se o poeta tivesse se deixado levar pela moda negrista daqueles anos, exaltando a África distante ou as raízes deixadas no continente, certamente, não teria provocado tanta reação desfavorável ${ }^{8}$. Ocorria, porém, que tudo aquilo era muito próximo, acusava e envergonhava a classe dirigente. Os poemas de Guillén falavam de uma grande parte da população que estava colocada à margem, reduzida a péssimas condições econômicas, devorada pela tuberculose e pelo analfabetismo e sem esperança de ascensão social. Em sua maioria, era gente mais ou menos escura, com frequiência filhos e netos de escravos, alguns, inclusive, que deveriam ser tratados como heróis nacionais porque haviam participado das lutas contra a Espanha, mas que viviam de miseráveis pensões do governo ${ }^{9}$. Além disso, o son era considerado música de negros, a exemplo do que ocorreu com o samba no Brasil em seus primeiros tempos. Sob os mais variados pretextos, acusou-se, então, Guillén de querer glorificar o lixo nacional e de, ao buscar inspiração nas classes sociais mais baixas, procurar de maneira intencional desprestigiar sua própria raça.

Naturalmente, muitas pessoas saíram em defesa do poeta, inclusive compositores conhecidos na Cuba dos anos 30 que trataram de musicar os poemas de Motivos de Son. Os intelectuais também logo descobriram que o autor daqueles versos não era nenhum primitivo, mas sim uma pessoa que estava a par do que ocorria no mundo, que mostrava influência modernista e que, com certeza, conhecia os clássicos espanhóis. Naquela altura, aos 28 anos de idade, Guillén já descobrira Lope de Vega, Quevedo, Luis de Góngora e outros clássicos do Século de Ouro - tornara-se, inclusive, um estudioso da tradicional poesia espanhola-, mas as suas influências decisivas, segundo ele mesmo, estavam bem mais próximas: eram os conjuntos populares Sexteto cubano e o Trío Matamoros ${ }^{10}$, que faziam um

\footnotetext{
${ }^{7}$ Nicolás Guillén, Obra poética 1922-1958, p. 102.

${ }^{8}$ Mirta Aguirre, Un poeta y un continente, p. 107.

${ }^{9}$ Ibid., pp. 106 e 107.

${ }^{10}$ Ibid., p. 78.
} 
tipo de música em que os estribilhos e as repetições eram marca inconfundível.

Para se situar o contexto em que surge Nicolás Guillén, devemos lembrar que, exatamente um mês antes da publicação de Motivos de Son no Diario de la Marina, houve em Havana uma greve geral em que se pedia a derrubada do ditador Gerardo Machado e a libertação de vários presos políticos. Vivia Cuba um clima de extrema agitação, inclusive com o assassinato de líderes operários por ordem do governo e também o fechamento de universidades ${ }^{11}$. Esse clima perduraria além da queda do ditador em 1933, persistindo no breve período da presidência de Grau San Martín e ainda no governo de Carlos Mendieta, que tinha por trás já a figura sinistra do ex-sargento Fulgencio Batista, que viria praticamente a dominar a política cubana até a revolução castrista de 1959 .

Em meio a esse pano de fundo, movimentava-se como jornalista o jovem Guillén, nascido em 1902 na aristocracia negra, um setor pequeno mas econômicamente bem situado e intelectualmente bem preparado. Vindo de Camagüey, pequena cidade rodeada de engenhos de cana-de-açúcar e fazendas de gado, Guillén era filho de um jornalista de formação liberal - dono de um jornal de província- - e, mais tarde, senador da república, que foi assassinado por questões políticas em 1917.

Em Havana, o mulato Guillén procurou inicialmente percorrer os melhores caminhos sociais: ingressou na faculdade de Direito, mas, ao ver que não tinha vocação para exercer a advocacia, desistiu dos estudos e tornou-se tipógrafo e, em seguida, jornalista. Com isso, mudou de ambiente. Começou a conviver com tipógrafos, jornalistas, operários e, na companhia deles, passou a freqüentar bailes de negros, festas populares e as famosas noites de Havana dos anos 30. Assim, pôde se aproximar das classes menos favorecidas e descobrir a alma popular. E foi isso que tratou de passar para os versos de Motivos de Son, depois de uma fase em que se dedicou a compor sonetos.

Os poemas de Motivos de Son são quadros breves em que cada protagonista fala em primeira pessoa com o linguajar espanhol deformado característico da população negra dos subúrbios de Havana. O próprio Guillén definiu esses poemas como «versos primários escritos na forma em que falam os negros e também não poucos brancos» ${ }^{12}$. Quando visitou o Brasil pela primeira vez em agosto de 1953, numa entrevista à escritora Maria de Lourdes Teixeira ${ }^{13}$, confessou que o seu objetivo foi o de criar uma

\footnotetext{
"Dirección política de las FAR, Historia de Cuba, p. 586.

12 Ángel Augier, prólogo de El libro de los sones, Nicolás Guillén, p. 29.

13 Maria de Lourdes Teixeira, artigo no jornal Folha da Manhã, em 16-8-1953.
} 
poesia popular que aproveitasse a cadência do son, aquela música que entre os cubanos, ao lado da rumba e do mambo, está mais próxima do povo, assim como o samba dos brasileiros. Um exemplo é «Negro Bembón»:

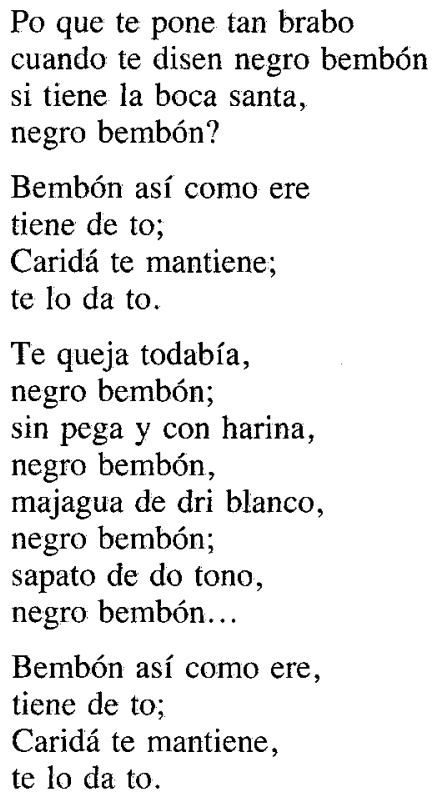

Bembón así como ere, tiene de to;

Caridá te mantiene, te lo da to.

O que primeiro se percebe nesses versos é o uso da apócope (a supressão de uma sílaba ao final da palavra). Esse recurso, que é utilizado na tentativa de reproduzir com maior fidelidade o jeito de falar do negro, desapareceu em algumas edições posteriores a de 1930. Em seguida, o que se constata é que são versos de construção muito simples, que não se preocupam em cumprir um número fixo de sílabas e tampouco estão dispostos em rimas, mas que obedecem, segundo Pedro Henríquez Ureña ${ }^{14}$, a uma lei rítmica primária: a da repetição. O que interessa aqui, como na maioria das canções de origem afro, é a estrutura rítmica que se manifesta em seu efeito auditivo. Deixando de lado esses aspectos formais, o que se pode deduzir desses versos é que, com eles, Guillén buscou tirar do negro um certo complexo de feiúra, assumindo aquilo que, de acordo com os padrões greco-latinos de beleza, seria feio como o beiço grande, o nariz achatado, etc. Isso fica ainda mais claro no poema seguinte, «Mulata»:

\footnotetext{
${ }^{14}$ Angel Augier, prólogo de El libro de los sones, Nicolás Guillên, p. 25.
} 
Ya yo me enteré, mulata, mulata, ya sé que dise que yo tengo la narise como nudo de cobbata.

Y fíjate bien que tú no ere tan adelantá, poqque tu boca e bien grande, y tu pasa, colorá.

Tanto tren con tu cueppo, tanto tren;

tanto tren con tu boca, tanto tren; tanto tren con tu sojo, tanto tren.

Si tú supiera, mulata, la veddá; que yo con mi negra tengo, y no te quiero pa na!

Ao assumir o «nariz como nó de gravata», largo e achatado, Guillén parece querer, com bom humor, combater o sentimento de rivalidade entre negros e mestiços. Nestes versos, de acordo com a reação de quem fala, parece que a mulata despreza o negro pelo simples fato de ele ser negro retinto. Em resposta, o negro, influenciado ainda por um padrão de beleza branco, responde com um certo rancor: «Y fíjate bien que tú / no ere tan adelantá (tão clarinha assim) / poqque tu boca e bien grande / y tu pasa (teu cabelo), colorá (pixaim acaju).» Em outras palavras, o protagonista quer dizer que a mulher não é tão branca quanto se imagina. Isso significa que o negro, ferido em seu amor próprio pelo desdém que lhe devota a mulata, tenta agredi-la com aquilo que supõe lhe possa doer mais:

A intenção do poeta é mesmo colocar à mostra esses preconceitos como uma forma de denunciá-los e levar seus irmãos de cor a constatar até que ponto a supremacia dos brancos lhes destruiu a identidade racial. De fato, ao dar uma conferência no Lyceum de Cuba no dia 20 de fevereiro de 1932, Guillén, respondendo aos que o acusavam de recriar com tintas muito fortes os defeitos dos negros, explica que age assim porque essa é a realidade. Diz que descreveu esses defeitos com profunda dor e não com o prazer mórbido de apresentá-los como algo irreparável ${ }^{15}$. A posição de Guillén, porém, não é a de atacar os brancos, mas sim a de defender a confraternização racial.

\footnotetext{
${ }^{15}$ Joaquín Santana, El joven Guillén, p. 67.
} 
Na realidade, ao denunciar esse tipo de preconceito que traduz a alienação em que se encontravam negros e mulatos, Guillén o faz sem maiores preocupações políticas e sociais. Aparentemente, seu principal objetivo foi o de captar o falar dos negros e transcrevê-lo foneticamente. Para reforçar essa tese, podemos lembrar que, à época da criação desses versos, o poeta mantinha-se distante das lutas sociais. Essa consciência social -que iria se radicalizar em 1937, quando ele ingressa no Partido Comunista (então chamado de Partido Socialista Popular) - começa a se manifestar a partir de seu segundo livro, Sóngoro Cosongo. Poemas mulatos, que saiu em outubro de 1932, custeado pelo próprio autor com o dinheiro que ganhara num prêmio de loteria.

Realmente, depois de Motivos de Son, a poesia de Guillén se fará cada vez mais coerente, transformando a solidariedade racial num tipo de nacionalismo. Sóngoro Cosongo, mais que Motivos de Son, vai valorizar o africano em Cuba: os versos captam a magia, a plasticidade dos ritos negros e, principalmente, as onomatopéias de sonoridade africana, que já estavam presentes no primeiro livro. Ao mesmo tempo, Guillén abandona os defeitos populares de pronúncia que são freqüentes em Motivos de Son. O importante é que, nesse livro, o poeta ressalta o ponto de vista de que a cultura cubana era realmente mulata, um produto das correntes culturais espanholas e africanas. E começa a desenvolver a idéia do «cubano» e o desejo de união do país. Tanto que no prólogo diz que «o espírito de Cuba é mestiço». E acrescenta: «do espírito para a pele nos virá a cor definitiva. Algum dia iremos dizer: cor cubana. Estes poemas querem se adiantar a esse dia» ${ }^{16}$.

As palavras sóngoro cosongo aparecem, inicialmente, como estribilho de um dos poemas de Motivos de Son que levava o título de Si tú supiera... Depois, tornaram-se título do próprio poema e, em seguida, viraram o nome do segundo livro de Guillén. No poema, esses vocábulos servem para marcar o ritmo, mas não têm significado determinado. São onomatopéias, que alguns críticos espanhóis qualificam de jitanjáforas. A jitanjáfora é uma composição estruturada com palavras inventadas e desprovidas de significado ${ }^{17}$, que funcionam como apoio rítmico. Nas cançōes de Vinícius de Moraes dos anos 60, essas palavras, de origem africana, estão muito presentes, provavelmente até por influência de Guillén, de quem o poeta brasileiro era muito amigo. $O$ que podemos acrescentar é que em

\footnotetext{
${ }^{16}$ Nicolás Guillén, Obra poética 1922-1958, p. 102.

${ }^{17}$ Luis Iñigo Madrigal, Summa poética, Nicolás Guillén, p. 26.
} 
sóngoro cosongo há duas vezes a palavra son, como se o poeta quisesse assinalar bem o novo ritmo que trazia para a poesia.

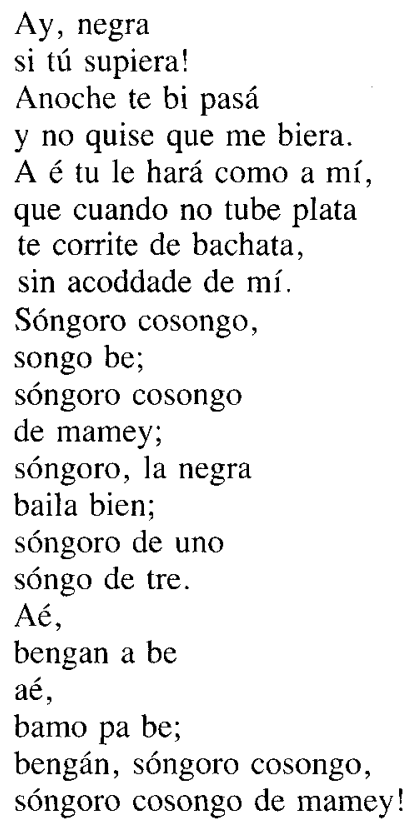

Esses recursos se repetem no livro que leva o nome do poema. Em «Canto Negro», por exemplo:

Yambambó, yambambé!

Repica el congo solongo, repica el negro bien negro; congo solongo del Songo baila yambó sobre un pie.

Mamatomba, serembe cuserembá.

El negro canta y se ajuma, el negro se ajuma y canta, el negro canta y se va.

Acuememe serembó, aé, yambo, aé. 
Tamba, tamba, tamba, tamba, tamba del negro que tumba; tumba del negro, caramba, caramba, que el negro tumba: yamba, yambó, yambambé!

Aqui, as palavras - a rigor, quase todo o poema- têm um valor por seu ritmo, como se fossem o som de um tambor, um atabaque, um som africano. Os demais versos do livro, embora menos onomatopaicos, seguem o mesmo ritmo, às vezes exaltando a agilidade do corpo africano, como na «Pequeña oda a un negro boxeador cubano» em que o poeta compara a agilidade do pugilista à de um esquilo (ardilla):

Tus guantes

puestos en la punta de tu cuerpo de ardilla, $y$ el punch de tu sonrisa.

El Norte es fiero y rudo, boxeador.

Ese mismo Broadway, que en actitud de vena se desangra para chillar junto a los rings en que tú saltas como un moderno mono elástico, sin el resorte de las sogas, ni los almohadones del clinch; ese mismo Broadway que unta de asombro su boca de melón ante tus puños explosivos y tus actuales zapatos de charol; ese mismo Broadway, es el que estira su hocico con una enorme lengua húmeda, para lamer glotonamente toda la sangre de nuestro cañaveral.

Nesse poema, Guillén compara o boxeador negro a um mono (macaco) elástico, mas sem ofendê-lo. Pelo contrário. É como se quisesse exaltá-lo, ao comparar suas qualidades à do animal. É a forma do poeta de descobrir e ensinar a africanidade, mas sem nunca ser racista ou preconizar um retorno à África, ao contrário de outros poetas do movimento negrista, como Aimé Césaire, de Martinica. É o que se pode constatar neste trecho intermediário do poema «La Canción del Bongó»:

En esta tierra, mulata de africano y español

(Santa Bárbara de un lado, 


\author{
del otro lado, Changó), \\ siempre falta algún abuelo, \\ cuando no sobra algún Don \\ y hay títulos de Castilla \\ con parientes en Bondó: \\ vale más callarse, amigos, \\ y no menear la cuestión, \\ porque venimos de lejos, \\ y andamos de dos en dos. \\ Aquí el que más fino sea, \\ responde si llamo yo.
}

West Indies, Ltd., o terceiro livro, de 1934, aparece numa época de muitas perseguições e mostra um Guillén violentamente político e social. São versos que denunciam e reclamam, refletindo o processo de radicalização experimentado pelo povo cubano durante esse período turbulento e revolucionário, que é frustrado pela ação clandestina do governo norte-americano. Os poemas são distintos dos anteriores, tanto em forma como em conteúdo. Guillén não busca a africanidade, nem fala só de negros, mas de cubanos, como se tivesse, por fim, alcançado a cor cubana de que falava no prólogo de Sóngoro Cosongo. Um exemplo é o poema que dá título ao livro. Vejamos o trecho inicial:

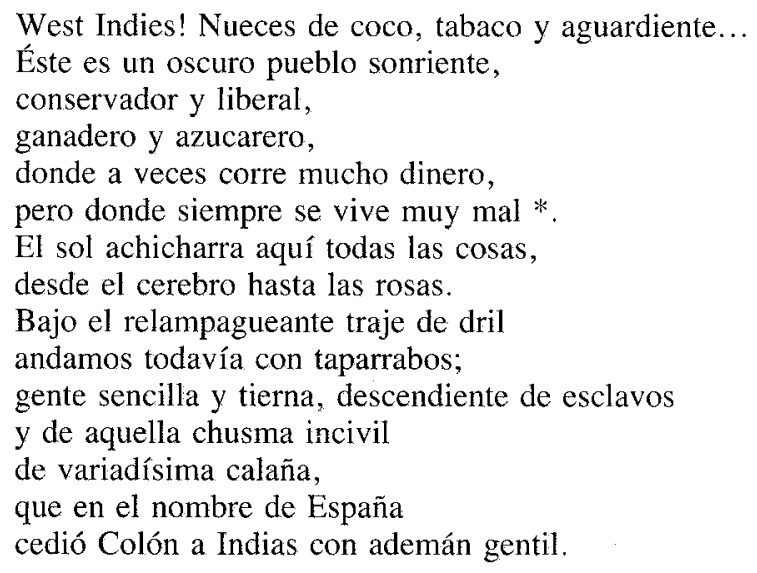

* Cierto que éste es un pueblo manso todavía... / No obstante, cualquier día / alza de un golpe la cerviz; / rompe por dondequiera con sus calludas manos / y hace como esos árboles urbanos / que arrancan toda una acera con una sola raíz. 
Aquí hay blancos y negros y chinos y mulatos.

Desde luego, se trata de colores baratos,

pues a través de tratos y contratos

se han corrido los tintes y no hay un tono estable.

(El que piense otra cosa que avance un paso y hable.)

Hay aquí todo eso, y hay partidos políticos,

y oradores que dicen: «En estos momentos críticos...»

Hay bancos y banqueros,

legisladores y bolsistas,

abogados y periodistas,

médicos y porteros.

Qué nos puede faltar?

Y aun lo que nos faltare lo mandaríamos buscar.

West Indies! Nueces de coco, tabaco y aguardiente.

Éste es un oscuro pueblo sonriente.

O título do poema já é uma ironia. «West Indies, Ltd.» procura denunciar a situação de colônia a que está submetido o Caribe, com a substituição do domínio espanhol pelo norte-americano que, com suas grandes empresas, sempre está a se intrometer nos negócios internos dos países em busca de dirigentes que se comprometam com a defesa de seus interesses. Ao trocar Cuba pelas Antilhas como tema de seus versos, Guillén, a exemplo de José Martí e Simón Bolívar em seu tempo, demonstra uma vocação americana que passará a ser a marca de sua poesia até o final. A partir daí, Guillén não se preocupa mais com a situação do negro, mas do trabalhador em geral, independente de cor. Formalmente, os versos de West Indies, Ltd. combinam estrofes tradicionais com o recurso ao son utilizado nos livros anteriores, como faz na segunda parte do poema que dá título ao livro:

El yanqui nos dará dinero para arreglar la situación; la Patria está por sobre todo... Que siga el son!

Los viejos líderes sonríen y hablan después desde un balcón.

La zafra! La zafra! La zafra! ¿Que siga el son!

West Indies, Ltd., com seu claro rechaço à ação imperialista dos Estados Unidos na ilha e em todo o Caribe, marca a evolução ideológica do autor em direção ao marxismo. Os seus livros posteriores só confirmam essa 
tendência: Cantos para soldados y sones para turistas (1937), España. Poema en cuatro angustias y una esperanza (1937), que reflete sua experiência na Guerra Civil da Espanha ao lado dos republicanos, e La paloma de vuelo popular (1958), com versos escritos durante o exílio de 1953 a 1958, que incluem uma homenagem ao pintor brasileiro Cândido Portinari.

Com o triunfo da revolução liderada por Fidel Castro, Guillén retorna do exílio no início de 1959 e, imediatamente, é ungido a poeta nacional de Cuba, transformando-se, com o tempo, num monumento em vida. Nos seus livros posteriores à revolução castrista, como Tengo (1964), El gran zoo (1967), que registra influências cubistas, La rueda dentada (1972) e El Diario que a Diario (1972), a ênfase sobre o negro decresce. O poeta alega que a luta não pode ser racista, mas revolucionária, e tem por objetivo a abolição da divisão da sociedade em classes. Para Guillén, a revolução dera um golpe mortal no racismo, embora isso seja muito discutível, já que a maioria dos líderes revolucionários - alguns que, inclusive, mais tarde, caem em desgraça - é branca, bem como brancos são ainda hoje os principais dirigentes do país.

Assim, sua poesia passa a ser comprometida com a revolução e o regime. E o poeta perde a aura de rebelde. Seus versos dessa fase tornam-se burocratizados como a revolução no poder. Canonizado poeta-máximo do movimento, Nicolás Guillén passa a fazer sones por encomenda para a campanha de alfabetização e para o programa de reforma agrária. Ou critica em versos aqueles que fogem para Miami. Como poeta oficial, faz loas a Fidel Castro, quando, em 1960, o governo cubano nacionaliza centrais açucareiras de propriedade norte-americana, e repete a atitude em 1962, quando os Estados Unidos organizam o bloqueio a Cuba. Em «Son del bloqueo», compara Fidel a Martí, ao mesmo tempo em que ironiza o presidente norte-americano John Kennedy:

Martí quiso a Cuba libre

y Fidel dijo: Ya está!

Quenedí, quenedá, con bloqueo y $\sin$ bloqueo

libre por siempre será.

Quenedí, quenedá. 
A última vez que Guillén assume uma posição de independência é em 1968, quando começa o famoso caso Padilla ${ }^{18}$. Numa época em que se consuma definitivamente a ascensão da ala stalinista da revolução, o poeta Heberto Padilla, que era ligado à ala mais branda, que reunia «Che» Guevara, Carlos Franqui, Guillermo Cabrera Infante e outros, ganha um prêmio nacional de poesia com o livro Fuera del juego, mas não o recebe por causa de uma ofensiva da polícia política. Guillén, então presidente da União de Escritores e Artistas de Cuba, recusa-se a participar da trama, a exemplo do escritor José Lezama Lima, que fazia parte do júri designado para outorgar o prêmio. Mesmo assim, continua como poeta-oficial da revolução até a sua morte recente, em 16 de julho de 1989, sempre passando ao largo das questões internas do país. Decididamente, não estão nessa fase de sua vida as suas melhores produções.

Dezembro de 1989.

\section{BIBLIOGR AFIA}

AbelLÁn, J. L.: La idea de América: origen y evolución (Madri: Ediciones Istmo, 1972).

AGUiRRE, Mirta: Un poeta y un continente (Havana: Editorial Letras Cubanas, 1982).

Augier, Ángel: El libro de los sones, Nicolás Guillén (Havana: Editorial Letras Cubanas, 1982).

CARPENTIER, Alejo: La música en Cuba (Havana: Editorial Luz-Hil, 1961).

DAvid, Juan: Nicolás Guillén (Havana: Editorial Letras Cubanas, 1982).

FAR, Dirección política de las: Historia de Cuba (Havana: Editorial de Ciencias Sociales, 1985).

Guillén, Nicolás: Obra poética 1922-1958 (Havana: Editorial Letras Cubanas, 1980).

- Motivos de Son (Havana: Editorial Letras Cubanas, 1980).

- El Diario que a diario (Havana: Editorial Letras Cubanas, 1985).

IMBERT, Enrique Anderson: Historia de la literatura hispanoamericana, vol. II (Cidade do México: Fondo de Cultura Económica, 1977).

MADRIGAL, Luis Iñigo: Summa poética, Nicolás Guillén (Madri: Ediciones Cátedra, 1986).

Melon, Alfred; Márquez, Roberto, y Ellis, Keith: Tres ensayos sobre Nicolás Guillén (Havana: Unión de Escritores y Artistas de Cuba, 1980).

OrTIZ, Fernando: Contrapunteo cubano del tabaco y el azúcar (Barcelona: Editorial Ariel, 1976).

${ }^{18}$ Adelto Gonçalves, entrevista com Heberto Padilla, Caderno 2 do jornal $O$ Estado de São Paulo, em 4-2-1989, pp. 4 e 5. 
- Entre cubanos: psicología tropical (Havana: Editorial de Ciencias Sociales, 1987).

OTERo, Lisandro: Disidencias y coincidencias en Cuba (Havana: Editorial José Martí, 1984).

SantanA, Joaquín G.: El joven Guillén (Havana: Editora Abril, 1987).

SAZ, Agustín de: Literatura iberoamericana (Barcelona: Editorial Juventud, 1978).

Ureña, Pedro Henríquez: Historia de la cultura en la América hispánica (Cidade do México: Fondo de Cultura Económica, 1979). 
